\title{
Influence of Xe ion-bombardment on the substrate microstructure and the residual stresses of TiN coatings deposited by plasma reactive sputtering onto AISI 4140 steel
}

\section{Thais Helena Carvalho Miranda ${ }^{1, a}$, Sandra Vales ${ }^{1, b}$, Erika Ochoa Becerra ${ }^{2, c}$, Roosevelt Droppa Junior ${ }^{3, d}$, Pedro Paiva Brito ${ }^{4, e}$, Jose Luis Garcia ${ }^{5, f}$, Fernando Alvarez ${ }^{2, g}$, Haroldo Pinto ${ }^{1, h}$}

\author{
${ }^{1}$ Universidade de São Paulo, Escola de Engenharia de São Carlos, Av. Trabalhador São-carlense \\ 400, São Carlos - SP, CEP 13566-590, Brazil \\ ${ }^{2}$ Universidade Estadual de Campinas (UNICAMP), Campus Universitário Zeferino Vaz, Barão \\ Geraldo, Campinas - SP, CEP 13083-970, Brazil \\ ${ }^{3}$ Universidade Federal do ABC (UFABC), R. da Abolição - Santa Terezinha, Santo André - São \\ Paulo, \\ CEP 09210-170, Brazil \\ ${ }^{4}$ Pontifícia Universidade Católica de Minas Gerais (PUC Minas), Av. Coração Eucarístico de \\ Jesus, 500 - Coração Eucarístico, Belo Horizonte - MG, CEP 30535-901, Brazil \\ ${ }^{5}$ Sandvik Machining Solutions, R\&D Materials \& Processes, Lerkrogsvägen 19, SE 12160 \\ Stockholm, Sweden
}

\begin{abstract}
athais.helena.miranda@usp.br, bsandra.vales@usp.br, 'abigail_ochoa@hotmail.com, droosevelt.droppa@ufabc.edu.br, ${ }^{\mathrm{d}}$ ppbrito@gmail.com, fjose.garcia@sandvik.com, galvarez@ifi.unicamp.br, hharoldo@sc.usp.br
\end{abstract}

Keywords: ion bombardment, nitriding, coating, TiN, residual stress

\begin{abstract}
The seek for sustainability in the global economic scenario has led to the need for developing materials that provide higher productivity, greater speed of operation, extended lifetimes and enhanced surface finishing of engineering parts. To achieve these goals it is essential to modify the metal surface with respect to its behavior in situations of friction, wear and oxidation at high temperatures. In this work, we studied the impact of different surface treatment strategies involving atomic peening with $\mathrm{Xe}$ ions and low temperature plasma nitriding on the surface microstructure of AISI 4140steel and the consequences of those surface treatments on the residual stresses of TiN coatings deposited onto the pre-treated substrates. The results show that ion bombardment at 1000 $\mathrm{eV}$ leads to mainly sputtering of surface material and no appreciable surface activation could be obtained for the subsequent plasma nitriding treatment. In the sample subjected to simple plasma nitriding, the highest nitride content was found and a Ti-enriched transition zone deposition is expected to build up during the coating deposition. Accordingly the residual stresses of the TiN coatings deposited onto the nitrided steel surface were significantly lower in comparison to those encountered in the coatings grown on the non-treated, only bombarded and bombarded followed by nitriding substrates.
\end{abstract}

\section{Introduction}

Coatings of transition metal nitrides have been widely used in engineering tools and dies mainly due to their high hardness, high thermal and chemical stability and corrosion resistance [1]. The adhesion of the hard coating to the metal substrate can be enhanced using certain surface pretreatment techniques that contribute to adjust both the mismatch of hardness through the ceramic/metal interface and the microstructure of the coating by controlled nucleation of grains.

Ion bombardment of metal surfaces produces at one hand a variety of microstructural changes, such as the appearance of defects, phase transformations, controlled material removal by sputtering and amorphization. In the case of steel substrates atomic peening with Xe ions was 
shown to cause grain refinement within the near-surface region, thus enhancing the diffusion of nitrogen into the steel surfaces [2-3]. Moreover, this process can also be applied to modify the substrate surface at the atomic level, making it harder and thus increasing the coating adhesion to the pre-treated substrate [4-5].

Another type of procedure used for the surface treatment of ferrous and non-ferrous materials is plasma nitriding. It represents a thermochemical diffusion process of nitrogen that is assisted by ion acceleration within the plasma and by its impact on the surface activation of the metal substrate [6]. This method usually allows for either reducing the nitriding temperatures or speeding up the process. Both contribute to preserve the metal substrate properties. The inward diffusion of nitrogen and its enhanced surface retention leads to subsequent reactions with the alloying elements, thus producing hard phases that are able to reinforce the metal surfaces. Two hard precipitates are typically formed in nitrided steel surfaces: the nitrogen-rich $\varepsilon-\mathrm{Fe}_{2-3} \mathrm{~N}$ and the iron-rich $\gamma$ '- $-\mathrm{Fe}_{4} \mathrm{~N}$ nitrides. Both exhibit elevated hardness (approximately $70 \mathrm{HRC}$ ) [7] and good corrosion resistance, thereby improving the tribological properties of steels [8-9].

Residual stresses are typically generated within coated metal-matrix composites owing to the thermal expansion mismatch between the hard coating and the metal substrate that arises during the cooling stage in the manufacturing of tools and dies. These residual stresses represent a major factor that determines the composite performance, since they superpose the thermal stresses during service. On the other hand, the application of surface pre-treatments modifies the phase composition within the metal surfaces. This may therefore have a great impact on the thermal mismatch between coating and substrate, thus contributing to tailor the residual stresses in the final products.

In the present work, we deal with the effect of different surface pre-treatments on the residual stresses of TiN coatings deposited onto AISI 4140 steel. We compare three processing routes of AISI 4140 steel surfaces: low temperature plasma nitriding at $380^{\circ} \mathrm{C}$, $\mathrm{Xe}$ ion bombardment and a combined treatment using Xe atomic peening followed by plasma nitriding. All three strategies were accompanied by a final TiN coating deposition according to the so-called duplex coating strategy.

\section{Experimental Details}

Substrate materials: The material used was AISI 4140 steel. Its chemical composition is given in Table 1. Discs were machined with $20 \mathrm{~mm}$ diameter and $2 \mathrm{~mm}$ thickness from the same rod. The samples were mirror polished prior to the surface pre-treatments and TiN film deposition.

Tab.1: Chemical composition of steel 4140[in wt \%]

\begin{tabular}{|l|l|l|l|l|l|l|l|}
\hline Element & C & Si & Mn & Cr & P & S & Mo \\
\hline $\mathbf{4 1 4 0}$ & 0,4 & 0,25 & 0,87 & 0,95 & 0,035 & 0,040 & 0,2 \\
\hline
\end{tabular}

Surface treatments: Prior to the deposition of TiN films, the sample surfaces underwent individual or combined treatments using Xe ion bombardment and plasma nitriding. Ion bombardment, plasma nitriding and film deposition were carried out in an ion beam assisted deposition system (IBAD).

The IBAD equipment consists of a deposition chamber equipped with two Kaufman ion sources of $3 \mathrm{~cm}$ diameter, a support for one to four targets and the samples temperature $\left(<1000^{\circ} \mathrm{C}\right)$ can be controlled. The base pressure within the chamber was $<10^{-4} \mathrm{~Pa}$.

The Xe gas was introduced into one of the Kaufman sources to perform the ion bombardment. Ions were accelerated to $1000 \mathrm{eV}$ and a beam of $20 \mathrm{~mA}$ was placed perpendicularly to the substrate surface. The atomic peening with Xe ions was conducted for $30 \mathrm{~min}$. The substrate temperature during bombardment was maintained below $260^{\circ} \mathrm{C}$ and the working pressure in this case was $1.5 \mathrm{x}$ $10^{-1} \mathrm{~Pa}$.

For nitriding the steel substrate a beam of $\mathrm{N}^{+}$with $200 \mathrm{eV}$ and $19 \mathrm{~mA}$ was directed to the substrate surfaces for $30 \mathrm{~min}$ at a temperature of $380^{\circ} \mathrm{C}$ and a pressure of $1.5 \times 10^{-2} \mathrm{~Pa}$ was used. The deposition of the TiN film was carried out by sputtering a Ti target with an Ar ion beam of 1.45 $\mathrm{keV}$ and $80 \mathrm{~mA}$ in a $\mathrm{N}_{2}$ atmosphere of $5.5 \times 10^{-2} \mathrm{~Pa}$. The substrate temperature was set to $400{ }^{\circ} \mathrm{C}$. The deposition time was 120 minutes. 
The procedures described above were carried out independently, as follows: initial substrate cleaning using a beam of $400 \mathrm{eV} \mathrm{Ar}^{+}$for 5 minutes, followed by bombardment with Xe ions at 1000 $\mathrm{eV}$ and/or plasma nitriding, and finally, the deposition of the TiN coating. Four samples were produced, one without treatment, two were treated individually and one sample underwent both types of treatment. All of them were finally coated with the TiN film. Tab.1 list the four samples investigated here.

Tab.1: Sample series and the respective surface treatments

\begin{tabular}{ll}
\hline Sample & Surface Treatment \\
\hline S & Steel + TiN \\
SN & Steel + nitrided layer + TiN \\
S1000 & Steel $+\mathrm{Xe}^{+}$bombarded layer + TiN \\
S1000N & Steel $+\mathrm{Xe}^{+}$bombarded and nitrided layer + TiN \\
\hline
\end{tabular}

Microstructure and phase analyses: Owing to the thin TiN coating and the restricted diffusion zones produced by nitriding at $380^{\circ} \mathrm{C}$, synchrotron X-ray diffraction (XRD) was used at the experimental station for powder diffraction (XPD) of the Brazilian National Synchrotron Radiation Laboratory (LNLS) in Campinas, Brazil, to determine the phase composition within each duplex coated sample. The radiation energy was set to $8.05 \mathrm{keV}(\lambda=1.5423 \mathrm{~A})$ and the beam size was 4 $\mathrm{mm}$ wide and $1 \mathrm{~mm}$ high. The diffractograms were obtained under a fixed grazing incidence angle $\omega$ of $3^{\circ}$, which corresponds to an average penetration depth $\tau 500 \mathrm{~nm}$. The TiN coatings and the microstructure changes in the AISI 4140 steel surface after the different duplex coating strategies were investigated on mirror-polished cross-sections etched with 5\% nital using a high-resolution FEG-SEM Philips XL -30 EGF.

Residual stress analyses: The impact of the four coating strategies on the average residual stress of the TiN films was determined using the modified $\sin ^{2} \psi$ method under a fixed grazing incidence angle of $1^{\circ}$ [10]. This allowed for maintaining a nearly fixed penetration depth of $400 \mathrm{~nm}$ that comprises the entire coating thickness. Thus, the effect of possible stress gradients within the coating can be suppressed. The stress analyses were carried out at the XPD experimental station of the LNLS in Campinas, Brazil. The radiation energy was set to $8.05 \mathrm{keV}(\lambda=1.5423 \mathrm{~A})$ and the beam size was $1 \mathrm{~mm} \times 1 \mathrm{~mm}$. Owing to the weak macroscopic texture of the IBAD TiN films, unrestricted measurements of the (220) lattice spacing could be performed for all sample directions defined by the inclination angles $\psi$ and $\omega$, as well as by the azimuth $\varphi$. The residual stresses were determined using the diffraction elastic constants (DEC) of the (220) TiN lattice planes, which were calculated based on the Hill's approach and the single crystal TiN elastic constants [11].

\section{Results and Discussion}

Microstructure: Fig. 1 shows the bulk microstructure of the AISI 4140 steel substrate. It has a typical quenched and tempered microstructure that consists of bainitic and martensitic needle-shaped grains with the occurrence of finely dispersed carbides within the bainitic regions.

A detailed view of the duplex-coated samples is presented in Fig.2. The TiN coating in all cases has an average thickness of $400 \mathrm{~nm}$. The AISI 4140 steel microstructure is not significantly altered with the $\mathrm{Xe}^{+}$ atomic peening at $1000 \mathrm{eV}$. However, the average

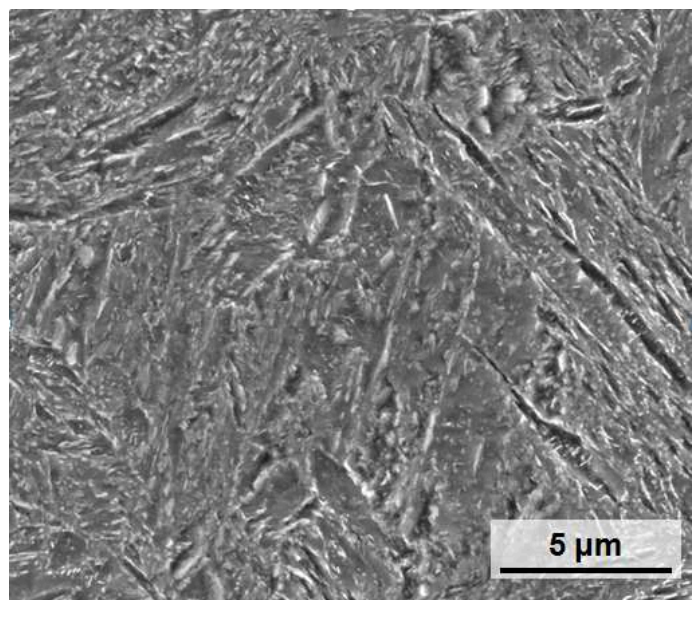

Fig.1: Quenched and tempered microstructure of the AISI 4140 steel. surface roughness increases to about $110 \mathrm{~nm}$, which 
coincides with AFM observations made in 100Cr6 steel substrates [12]. This causes localized coating delamination along the TiN/steel interface (Fig.2b).

Plasma nitriding carried out at $380^{\circ} \mathrm{C}$ does not lead to the formation of a white compound layer, but to only a restricted diffusion zone. The same cannot be clearly observed for the combined surface treatment. The extension of the diffusion zone can only be well-defined for the sample that underwent simple plasma nitriding. In this case the diffusion zone reaches up to $500 \mathrm{~nm}$ depth, as delimited by the dashed black lines in Fig 2c. In this region finely dispersed platelets can be observed, thus confirming the formation of a more appreciable volume fraction of nitrides. Atomic peening with Xe ions prior to nitriding seems to cause mainly material removal by sputtering, thus causing the diffusion zone to be interrupted and even much less extended than after simple plasma nitriding.

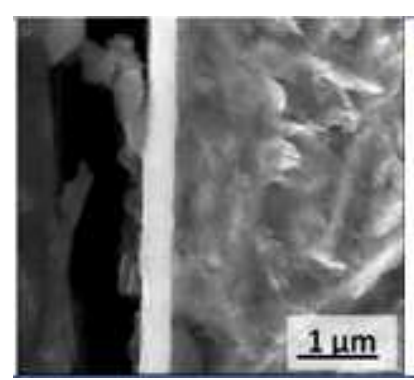

(a) $\mathrm{S}$

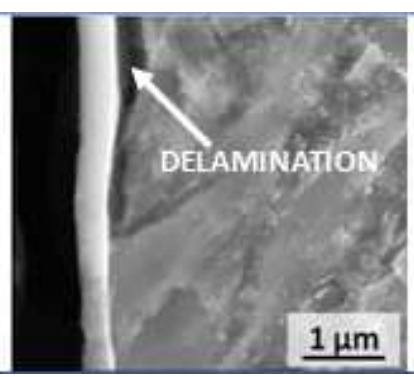

(b) $\mathrm{S} 1000$

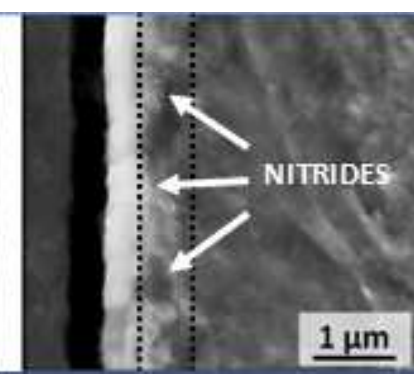

(c) $\mathrm{SN}$

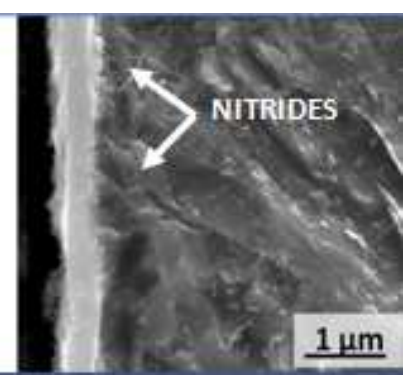

(d) $\mathrm{S} 1000 \mathrm{~N}$

Fig.2: SEM images of the TiN coatings and the pre-treated surfaces.

The phase composition of the AISI 4140 steel surfaces subjected to the different pretreatment strategies can be determined from the diffractograms obtained under grazing incidence (GI) and displayed in Fig.3. The sample S1000 can be used as reference, since it does not undergo phase transformations, such as the formation of iron nitrides. SN and S1000N samples evolve a similar phase composition within their pre-treated surfaces. Both exhibit the formation of a more appreciable volume fraction of the nitrogen-rich $\varepsilon-\mathrm{Fe}_{2-3} \mathrm{~N}$, but a low content of $\gamma^{\prime}-\mathrm{Fe}_{4} \mathrm{~N}$ can also be detected (Fig. $3 \mathrm{~b}-\mathrm{c}$ ). In addition, the $\mathrm{SN}$ sample subjected to simple plasma nitriding contains a more elevated $\varepsilon-\mathrm{Fe}_{2-3} \mathrm{~N}$ content. This can be derived from the diffraction line intensities of $\varepsilon-\mathrm{Fe}_{2-3} \mathrm{~N}$ that are higher for the SN sample in comparison to the S1000N (Fig.3b). This observation also corroborates the SEM investigations that revealed a thicker and continuous diffusion zone in the SN sample. Another feature present in the diffractograms is the extended line broadening of the TiN reflections. This suggests that the coating is nanostructured. An estimation using the Scherrer equation yields $10 \mathrm{~nm}$ of coherently diffracting domain size within the grains of the coating. In addition, the diffractograms display the occurrence of all TiN diffraction lines, thus suggesting that a strong preferential orientation of grain growth does not occur in contrast to earlier observations in other TiN coatings deposited by sputtering [13]. 
(a)

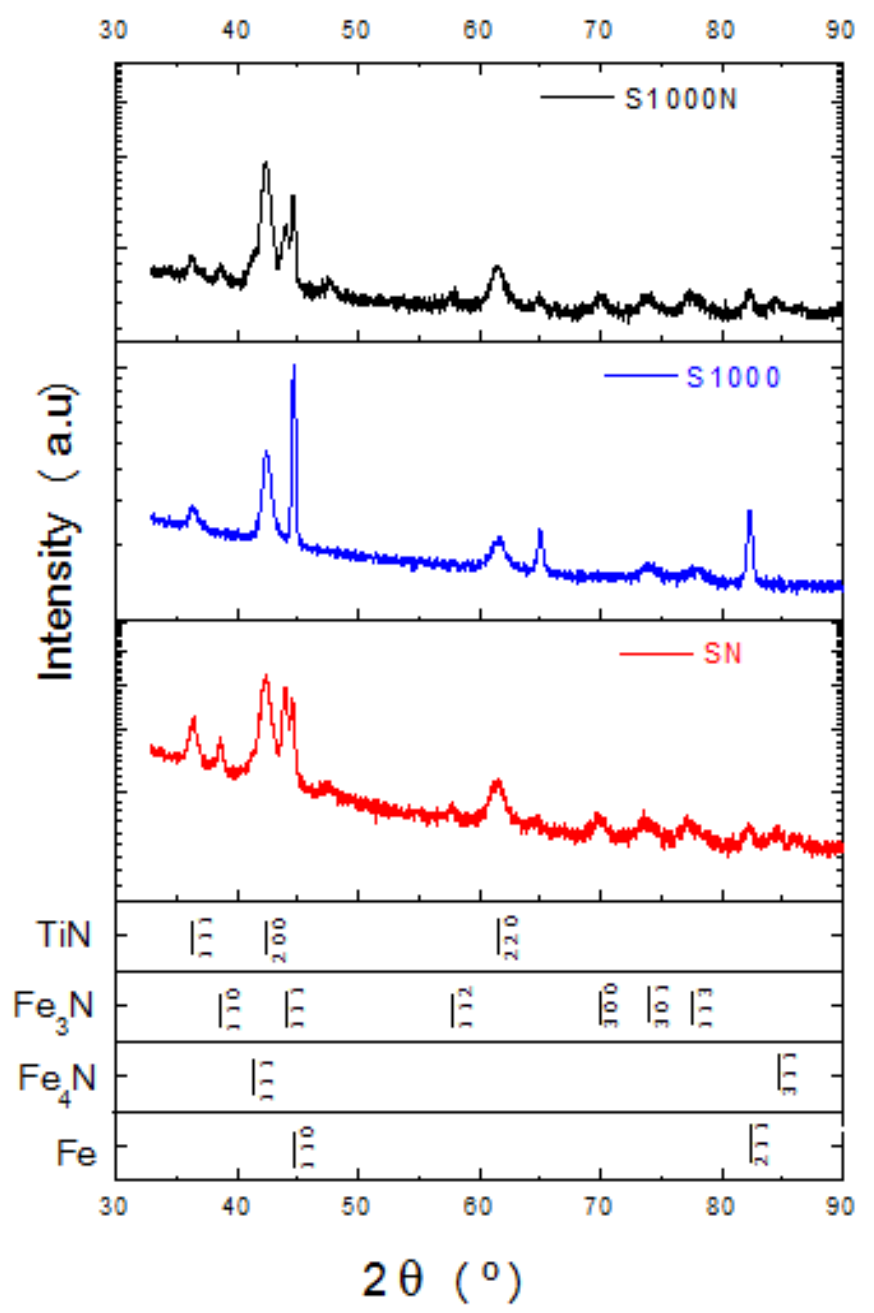

(b)

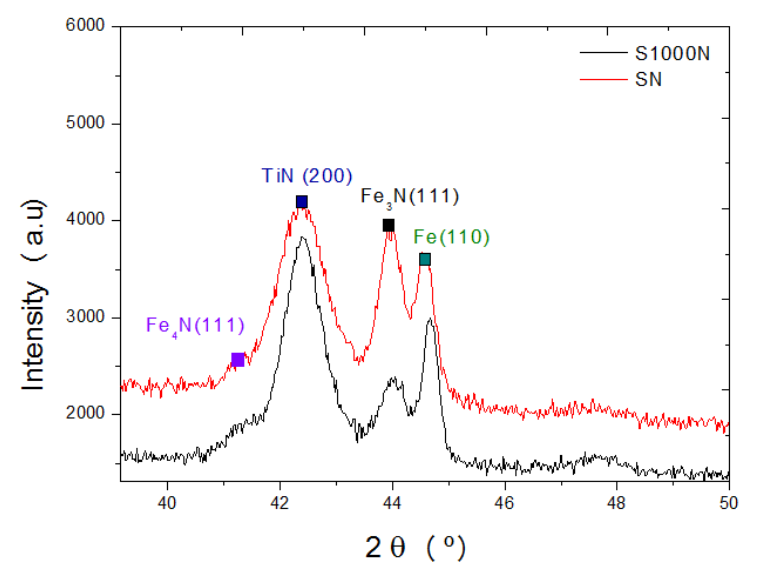

(c)

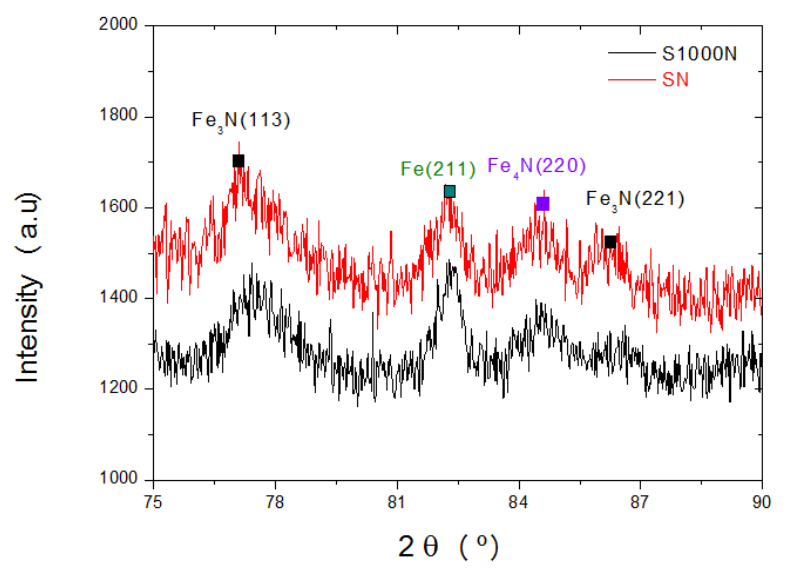

Fig.3: (a) GI X-ray diffractograms of the samples SN, S1000 and S1000N; (b) and (c) detailed views of the occurrence of $\gamma^{\prime}-\mathrm{Fe}_{4} \mathrm{~N}$ in the $\mathrm{SN}$ and $\mathrm{S} 1000 \mathrm{~N}$ samples.

Residual stresses: PVD coatings undergo intrinsic residual stresses due to the ion bombardment promoted by the plasma. The incoming ions or knock-on atoms shift other atoms from their lattice positions, thus producing residual interstitials. The result is in general an expansion of the film outwards the substrate. In the plane of the coating, however, the layer is not free to expand and the entrapped atoms cause elevated compressive stresses [14]. In addition to those intrinsic stresses, socalled extrinsic residual stresses also build up during cooling from the deposition temperature owing to the difference in thermal expansion between the coating and the substrate [15-16]. The extrinsic component can be therefore modified if the phase composition within the near-surface zone and consequently its average thermal expansion coefficient (TEC) are altered. Thus, the surface pre-treatments are supposed to influence the residual stress level of the hard coating.

Fig. 4a displays the $\cos \alpha^{*} \sin ^{2} \Psi$ distributions of the (220) TiN lattice planes, where $\alpha=\theta_{0}$ $\omega$ corresponds to the angle between the sample surface and the diffracting (220) plane, $\theta_{0}$ is the Bragg angle of the observed $220 \mathrm{TiN}$ plane at $\psi=0^{\circ}, \psi$ represents the sample tilt in the diffractometer about the $\psi$-axis and $\omega$ is the grazing angle adjusted by the sample tilt about the $\omega$ axis.

In agreement with previous studies [10,13], the distributions are linear. In addition, the diffraction line is assessable at all tilting angles, thus confirming the absence of sharp preferential growth orientation in the coating. Fig. $4 \mathrm{~b}$ displays the residual stresses in the TiN films as a function of the duplex coating strategy. The residual stresses are highly compressive for all surface treatments. The highest stress level $(-6.0 \mathrm{GPa})$ is observed for the $\mathrm{S}$ sample without any surface pre-treatment. Simple ion bombardment and the combined treatment do not lead to any appreciable change in the stress value of TiN that remains above $-5.5 \mathrm{GPa}$. 
A considerable reduction of the coating stresses is achieved with simple low-temperature plasma nitriding. The residual stresses decrease down to about $-4.0 \mathrm{GPa}$. Investigations made in other duplex PVD coatings deposited onto previously nitrided substrates [17-18] reveal the existence of a transition zone between substrate and coating. Its development is related to the effect of the high energy ions during IBAD that cause the transference of chemical elements across the interface between coating and nitrided diffusion zone as well as the increased desorption of the substrate surface. In the present case, a Ti-rich interlayer appears therefore to be implanted in the substrate surface, thus enabling the reaction of $\mathrm{Ti}$ with nitrogen within the nitrided diffusion zone. This enhances the coating adhesion and increases the chemical similarity between substrate and coating, which contributes to diminish the residual stresses in the TiN coating. In addition, the sample SN exhibits higher nitride content compared to the S1000N sample. This diminishes the thermal expansion mismatch between coating and steel surface, since TEC $\left(\gamma^{\prime}-\mathrm{Fe}_{4} \mathrm{~N}\right)<\mathrm{TEC}\left(\varepsilon-\mathrm{Fe}_{2}\right.$ $\left.{ }_{3} \mathrm{~N}\right)<\mathrm{TEC}(\alpha-\mathrm{Fe})$. The results indicate therefore that the transition layer and the extrinsic stress component can be tailored to reduce the residual PVD coating stresses by adjusting the surface pretreatment.

(a)

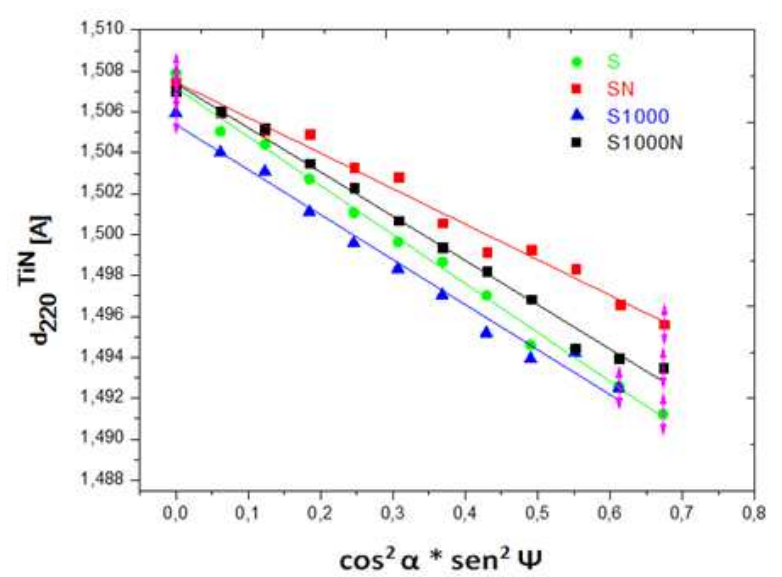

(b)

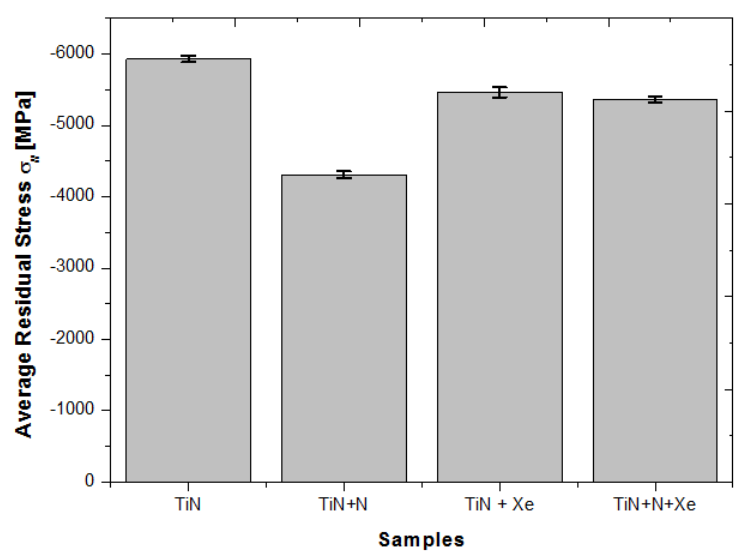

Fig.4: (a) Linear dependence of $d_{220}{ }^{\text {TiN }}$ upon $\cos \alpha^{*} \sin ^{2} \Psi$ for all the samples; (b) in-plane residual stresses as a function of the surface treatment.

\section{Conclusions}

The effect of individual and combined pre-treatments based on the bombardment with Xe ions and plasma nitriding at $380^{\circ} \mathrm{C}$ on the surface microstructure of the AISI 4140 steel and the residual stresses of TiN films deposited onto this steel substrate were investigated.

Results demonstrate that the bombardment with Xe ions at $1000 \mathrm{eV}$ causes sputtering of surface material, rather than implantation and surface activation due to the generation of lattice imperfections. This increases the roughness of the substrate and promotes localized coating delamination. The density of lattice imperfections within the bombarded surface is not increased thereby and the subsequent nitrogen diffusion at $380^{\circ} \mathrm{C}$ is rather diminished probably due to the increased substrate roughness. Those observations suggest that the bombardment energy has to be reduced for the AISI 4140 steel to enable its surface activation and enhance the nitrogen diffusion.

The residual stresses in the TiN coating could be significantly reduced by plasma nitriding the steel substrate, since a transition zone with implanted Ti atoms seems to be formed in the AISI 4140 steel surface during ion-beam assisted coating deposition and a more extended diffusion zone composed of both $\varepsilon-\mathrm{Fe}_{2-3} \mathrm{~N}$ and $\gamma-\mathrm{Fe}_{4} \mathrm{~N}$ nitrides was produced. This highlights the importance of tailoring the Ti-enriched transition zone, the thermal expansion mismatch between coating and substrate and, consequently, the extrinsic residual stress component by modifying the microstructure of the substrate surface. 


\section{Acknowledgments}

T. Miranda acknowledges the funding of the University of Sao Paulo through its Scholarship Program for International Exchange. H. Pinto and J. Garcia acknowledge the financial support of the NanoCom Network funded by $7^{\text {th }}$ Framework Programme (FP7) of the European Union. S. Vales is grateful to Conselho Nacional de Desenvolvimento Científico e Tecnológico (CNPq) for granting the scholarship to carry out this research. H. Pinto and F. Alvarez are also CNPq fellows.

\section{References}

[1] C.-H. Ma, J.-H. Huang, H. Chen. Texture evolution of transition-metal nitride thin films by ion beam assisted deposition. Thin solid films, v. 446, p. 184-193, 2004.

[2] N. Mottu, M. Vayer, R. Erre. Xe and Mo implantation on austenitic stainless steel: structural modification. Surface and Coatings Technology, v. 183, p. 165-173, 2004.

[3] R.L. Basso, R.J. Candal, C.A. Figueroa, D. Wisnivesky, F. Alvarez. Influence of microstructure on the corrosion behavior of nitrocarburized AISI H13 tool steel obtained by pulsed DC plasma. Surface \& Coatings Technology, v. 203, p. 1293-1297, 2009.

[4] E. A. Ochoa, C. A. Figueroa, T. Czerwiec, F. Alvarez. Enhanced nitrogen diffusion induced by atomic attrition. Applied Physics Letters, v. 88, p. 254109, 2006.

[5] E. A. Ochoa, C. A. Figueroa, F. Alvarez. Nitriding of AISI 4140 steel by a low energy broad ion source. Journal of Vacuum Science Technology A, v. 24 (6), p. 2113- 2116, Nov/Dez 2006.

[6] G. Krauss. Steels: heat treatment and processing principles. $1^{\text {a }}$. ed. Ohio: ASM International, 1994.

[7] S.M.M. Ramos, L. Amaral, M. Behar, G. Marest, A. Vasquez, F.C. Zawislak. The effects of xenon bombardment on the dissolution and reprecipitation of carbonitrides produced in nitrogen-implanted low carbon steel. Surface and Coatings Technology, v. 45, p. 255-262, 1991.

[8] K. Gammer, M Stoiber, J Wagner, H Hutter, R Kullmer, C Mitterer. Investigations on the effects of plasma-assisted pre-treatment for plasma-assisted chemical vapour deposition TiN coatings on tool steel. Thin solid films, v. 461, p. 277-281, 2004.

[9] Y. L. K. X. Shengli Ma. The composite of nitrided steel of H13 and TiN coatings by plasma duplex treatment and the effect of pre-nitriding. Surface and Coatings Technology, v. 137, p. 116-121, 2001.

[10] C. H. Ma, J.-H. Huang, H. Chen. Residual Stress Measurement in Textured Thin Film by Grazing-Incidence X-Ray Diffraction, Thin Solid Films 418, v. 73, 2002.

[11] B. Eigenmann, E. Macherauch, Rontgenographische Untersuchung von Spannungszustanden in Werkstoffen. Mat.-wiss. u. Werkstofftech., v. 26, p. 199-216, 1995.

[12] R. Droppa Jr, H.C. Pinto, J. Garcia, E.A. Ochoa, M. Morales, S. Cucatti, F. Alvarez. Influence of ion-beam bombardment on the physical properties of 100Cr6 steel, Materials Chemistry and Physics, in press, 2014.

[13] A.Akbari, J. P. Riviere, C. Templier, E. Le Bourhis, G. Abadias. Hardness and residual stresses in TiN-Ni nanocomposite coatings deposited by reactive dual ion beam sputtering, Reviews on Advanced Materials Science, v. 15, p. 111-117, 2007.

[14] C.A. Davis. A simple model for the formation of compressive stress in thin films by ion bombardment. Thin Solid Film, v. 226, p. 30-34, 1993.

[15] M. Birkholz. Thin Film Analysis by X-Ray Scattering. WILEY-VCH, 2006. ISBN:3-52731052-5.

[16] G. Totten; M. Howes; T. Inoue. Stress determination in coatings. In: Handbook of Residual Stress and Deformation of Steels. ASTM International, 2002. p. 118-124. ISBN DOI: 10.1361/hrsd2002p118.

[17] M. Polok-Rubiniec, K. Lukaszkowicz, L.A. Dobrzański. Comparison of nanostructure and duplex PVD coatings deposited onto hot work tool steel substrate, J. of Achievements in Materials and Manufacturing Engineering, v. 41 (1-2), p. 187-194, 2010.

[18] G.E. Totten, H. Liang. Surface Modification and Mechanisms: Friction, Stress, and Reaction Engineering. Marcel Dekker, Inc., 2004. ISBN: 0-8247-4872-7. 